\title{
D'une citoyenneté empêchée à une éducation citoyenne
}

Nathanaël Wallenhorst et Éric Mutabazi (dir.), Le Bord de l'eau, 2021, $230 \mathrm{p}$.

Jean-Pierre Véran

\section{OpenEdition}

Journals

Édition électronique

URL : https://journals.openedition.org/ries/10845

DOI : $10.4000 /$ ries. 10845

ISSN : 2261-4265

Éditeur

France Education international

\section{Édition imprimée}

Date de publication : 1 septembre 2021

ISBN : 978-2-85420-630-2

ISSN : $1254-4590$

\section{Référence électronique}

Jean-Pierre Véran, « D’une citoyenneté empêchée à une éducation citoyenne », Revue internationale d'éducation de Sèvres [En ligne], 87 | septembre 2021, mis en ligne le 01 septembre 2022, consulté le 25 mars 2023. URL : http://journals.openedition.org/ries/10845 ; DOI : https://doi.org/10.4000/ries. 10845

Ce document a été généré automatiquement le 25 mars 2023.

Tous droits réservés 


\section{D'une citoyenneté empêchée à une éducation citoyenne}

Nathanaël Wallenhorst et Éric Mutabazi (dir.), Le Bord de l'eau, 2021, $230 \mathrm{p}$.

Jean-Pierre Véran

\section{RÉFÉRENCE}

D’une citoyenneté empêchée à une éducation citoyenne, Nathanaël Wallenhorst et Éric Mutabazi (dir.), Le Bord de l'eau, 2021, 230 p.

1 Pour les lecteurs de la Revue internationale d'éducation de Sèvres, on soulignera d'abord que cet ouvrage pose la question de la citoyenneté à l'ère de la mondialisation. Et, à titre d'exemple, on donnera le chapitre 2, qui répond à la question posée par son titre : "Comment l'ethnicité a empêché la réalisation d'une communauté de citoyens au Rwanda? » On soulignera aussi que les penseurs à qui il est fait appel, de Kant à Arendt en passant par Gramsci, ont en commun d'avoir pensé la question de la citoyenneté dans des contextes historiques et nationaux très divers, mais à une échelle dépassant les frontières nationales.

2 On soulignera également un second mérite de ce travail collectif de onze chercheurs. Il dresse d'abord un tableau de la citoyenneté empêchée de notre temps présent avant de proposer un dépassement de ces empêchements divers au travers d'une citoyenneté cosmopolitique et existentielle.

3 La première partie fait le tour des entraves à la citoyenneté : outre l'appartenance ethnique, l'appartenance religieuse, culturelle viennent à l'esprit, mais c'est le cas aussi des promesses du numérique, qui enferme tout autant dans des bulles informationnelles qu'il promeut une conversation planétaire. L'accent est mis sur les oubliés de la citoyenneté: frappés par la méfiance, le sentiment de peur et d'impuissance, qui se traduisent par la crise de la représentation politique et l'abstention, ils sont victimes d'une culture de la passivité, renforcée par la 
déterritorialisation numérique et l'ubiquité des menaces d'aujourd'hui (terrorisme, pandémies). Devant eux quatre voies, dont trois sont des impasses. On les incite à se responsabiliser, à renoncer à la prétendue «culture de l'excuse » qui justifierait leur marginalisation, par leur origine, leur condition sociale, leur genre. Ou bien on leur propose, en réponse à leur demande d'autorité, un État fort, régnant sur une masse de citoyens dociles semblables aux personnages de Fahrenheit 451. Ou c'est un projet intercommunautaire, enfermant chacun dans son groupe d'appartenance, au prix du morcellement social. Le seul modèle qui vaille est celui du vivre-ensemble dans la coopération, la complémentarité, la réciprocité, la mutualité: une société de l'attention, attachée à produire du commun. C'est l'intérêt des subaltern studies, de l'histoire par le bas, qui, de l'Inde au Royaume-Uni en passant par l'Italie du Sud, analyse les cultures populaires pour dessiner la voie d'une émancipation par l'éducation qui ne repose pas sur un catéchisme civique inculqué, mais sur la prise en compte de la complexité du réel favorisant l'expérience de la vie en société.

4 La deuxième partie de l'ouvrage dégage des éléments d'éducation politique, puisque l'éducation est un moyen politique. La force de l'ouvrage est ici, d'abord, de choisir le prisme cosmopolitique, qui situe la citoyenneté nationale dans un monde global; ensuite de s'attacher à trois âges de la vie - l'enfance, la jeunesse, l'âge adulte -, pour en analyser les enjeux différenciés de formation citoyenne.

On retrouve donc ici la source des Lumières, avec Kant, notamment, qui, à travers un projet de paix perpétuelle (1795), fonde un droit cosmopolitique, où l'homme est partout citoyen, bénéficiant d'une hospitalité universelle qui reste à inscrire dans nos droits au $\mathrm{xxI}^{\mathrm{e}}$ siècle. L'éducation cosmopolitique repose sur trois principes: moral (égale dignité de tous les êtres humains), politique (citoyenneté cosmopolitique) et culturel (interculturalité). Elle consiste à s'emparer des problèmes mondiaux, à débattre, à s'organiser, à chercher à apprendre de l'étranger pour maintenir vivante sa propre culture d'origine. Elle repose sur l'essor de la pensée critique, qui consiste notamment à déconstruire les stéréotypes.

6 Le temps de l'enfance est-il à l'abri de la citoyenneté ? S'inspirant de Rousseau, on peut penser le temps d'enfance incompressible, protégé mais marqué par les épreuves symboliques initiatrices d'une citoyenneté existentielle nourrie notamment par les albums de littérature de jeunesse. Le rôle de la pédagogie consiste à créer une responsabilité symbolique dans l'espace pédagogique, protégé de l'évaluation de tout ce qui se fait à l'école : l'enfant acquiert la responsabilité de la transformation et de la transmission.

7 Pour aborder l'éducation au politique de la jeunesse, l'ouvrage propose de partir de l'expérience du déclassement vécue par des étudiants en réorientation. Le point commun du discours tenu par ces jeunes peut se résumer à « je ne suis pas attendu, je ne suis pas à ma place ». Ce phénomène générationnel pose la question, formulée par Arendt, du rapport à la vie et au monde. Selon la philosophe, la mission de l'éducation est prépolitique :

La finalité de l'enseignement doit-elle devenir la relation ou l'apprentissage de la vie ? Mais un enseignement peut-il avoir autre chose que les savoirs pour finalité, et notamment les savoirs du monde?

8 Faut-il opposer "enseigner à vivre » (Morin) et "enseigner le monde » (Arendt), éduquer au politique signifiant prendre la responsabilité du monde face à l'autre l'étranger et la génération à venir? Pour dépasser cette antinomie, les auteurs 
développent le concept de citoyenneté existentielle, qui consiste à assumer la responsabilité du monde et la finitude de son existence. L'objectif ne saurait se réduire à l'institution de l'Homo œconomicus, mais inclut celle de l'Homo collectivus et religatus. Il s'agit d'apprendre à nous opposer sans nous massacrer ni instaurer de relation de domination ${ }^{1}$.

9 La réflexion de Paul Ricœur sur la citoyenneté apporte des clés intéressantes de compréhension des enjeux actuels. Une éducation à la responsabilité suppose la compréhension de soi et du monde, insiste sur la notion de capacité plutôt que sur celle de performance, et vise à former un sujet capable de parler, d'agir, de raconter, d'être responsable. Pour faire advenir le sujet éthique et le citoyen, on ne soulignera jamais assez l'importance capitale de l'institution du langage à l'école.

La conclusion dégage quatre dimensions à la citoyenneté : participation (vs la défiance), solidarité (vs la méfiance vis-à-vis de l'Autre), responsabilité (vs l'irresponsabilité pratique), et éducation (pour donner un sens à la mondialisation).

11 Dans quelque pays qu'ils vivent, les lecteurs trouveront dans cet ouvrage des principes susceptibles d'orienter l'éducation citoyenne au $\mathrm{xxI}^{\mathrm{e}}$ siècle. La dimension cosmopolitique et existentielle constitue une approche stimulante de cette question.

\section{NOTES}

1. Les lecteurs qui, du Québec ou Liban, se questionnent sur la laïcité française trouveront dans l'ouvrage cette définition de Paul Ricœur: «une laïcité dynamique, active, polémique, où le maximum de ce que j'ai à demander à autrui n'est pas d'adhérer à ce que je crois vrai, mais de donner ses meilleurs arguments ».

\section{AUTEURS}

\section{JEAN-PIERRE VÉRAN}

Jean-Pierre Véran est inspecteur d'académie (H), membre du comité de rédaction de la Revue internationale d'éducation de Sèvres et expert auprès de France Éducation International en coopération éducative. Il intervient sur les questions de gouvernance des organisations éducatives, de politiques éducatives et d'éducation aux médias et à l'information. Auteur de plusieurs ouvrages, il tient également un blog consacré à l'éducation sur Mediapart : http:// blogs.mediapart.fr/blog/jean-pierre-veran/ ; courriel : jeanpierreveran2[at]gmail.com 